\title{
Maternal first-trimester dietary intake and childhood blood pressure: the Generation R Study
}

\author{
Leontine C. L. van den Hil ${ }^{1,2,3}$, H. Rob Taal ${ }^{1,2,3}$, Layla. L. de Jonge ${ }^{1,2,3}$, Denise H. M. Heppe , $^{1,2,3}$, \\ Eric A. P. Steegers ${ }^{4}$, Albert Hofman ${ }^{3}$, Albert J. van der Heijden ${ }^{2}$ and Vincent W. V. Jaddoe ${ }^{1,2,3 *}$ \\ ${ }^{1}$ The Generation R Study Group, Erasmus Medical Center, PO Box 2040, 3000 CA Rotterdam, The Netherlands \\ ${ }^{2}$ Department of Pediatrics, Erasmus Medical Center, PO Box 2040, 3000 CA Rotterdam, The Netherlands \\ ${ }^{3}$ Department of Epidemiology, Erasmus Medical Center, PO Box 2040, 3000 CA Rotterdam, The Netherlands \\ ${ }^{4}$ Department of Obstetrics and Gynaecology, Erasmus Medical Center, PO Box 2040, 3000 CA Rotterdam, The Netherlands
}

(Submitted 12 July 2012 - Final revision received 24 January 2013 - Accepted 31 January 2013 - First published online 26 March 2013)

\begin{abstract}
Suboptimal maternal dietary intake during pregnancy might lead to fetal cardiovascular adaptations and higher blood pressure in the offspring. The aim of the present study was to investigate the associations of maternal first-trimester dietary intake with blood pressure in children at the age of 6 years. We assessed first-trimester maternal daily dietary intake by a FFQ and measured folate, homocysteine and vitamin $\mathrm{B}_{12}$ concentrations in the blood, in a population-based prospective cohort study among 2863 mothers and children. Childhood systolic and diastolic blood pressure was measured using a validated automatic sphygmomanometer. First-trimester maternal daily intake of energy, fat, protein and carbohydrate was not associated with childhood blood pressure. Furthermore, maternal intake of micronutrients was not associated with childhood blood pressure. Also, higher maternal vitamin $\mathrm{B}_{12}$ concentrations were associated with a higher diastolic blood pressure $\left(0.31 \mathrm{mmHg}\right.$ per standard deviation increase in vitamin $\mathrm{B}_{12}$ (95\% CI 0.06, 0.56)). After taking into account multiple testing, none of the associations was statistically significant. Maternal first-trimester folate and homocysteine concentrations were not associated with childhood blood pressure. The results from the present study suggest that maternal Fe intake and vitamin $\mathrm{B}_{12}$ concentrations during the first trimester of pregnancy might affect childhood blood pressure, although the effect estimates were small and were not significant after correction for multiple testing. Further studies are needed to replicate these findings, to elucidate the underlying mechanisms and to assess whether these differences in blood pressure persist in later life.
\end{abstract}

Key words: Maternal diet: Childhood blood pressure: Iron: Calcium: Folate: Homocysteine: Vitamin $\mathbf{B}_{12}$

Suboptimal maternal and fetal nutrition might lead to fetal cardiovascular developmental adaptations and subsequent CVD in later life ${ }^{(1-3)}$. Support for this hypothesis is largely based on experimental animal studies and historical cohort studies in human subjects showing associations of maternal exposure to extreme famine during pregnancy with the development of hypertension in later life $\mathrm{e}^{(4-6)}$. An imbalance in nutrient intake during pregnancy might also be an explanation for the development of hypertension ${ }^{(4)}$. Not much is known about the associations of less extreme variations in maternal dietary intake with CVD in the offspring. Several studies have focused on the associations of maternal micro- or macronutrient intake with childhood blood pressure but the results are inconclusive ${ }^{(7-17)}$. For example, two previous studies suggested that higher maternal fat intake during pregnancy was associated with diastolic blood pressure in the offspring, although the studies observed opposite effects ${ }^{(7,8)}$. Also, maternal intake of micronutrients during pregnancy, such as $\mathrm{Ca}$, $\mathrm{Na}$ and $\mathrm{Fe}$, has been suggested to be associated with blood pressure in children, but results were not consistent ${ }^{(9-11,13-15)}$. Other micronutrients, including folate, homocysteine and vitamin $\mathrm{B}_{12}$, might affect vascular development ${ }^{(18)}$. High homocysteine and low folate levels are associated with endothelial dysfunction $^{(19,20)}$ and might subsequently lead to higher blood pressure in later life. Since vitamin $\mathrm{B}_{12}$ lowers homocysteine levels, this might also influence blood pressure.

We assessed in a large population-based prospective cohort study among 2863 Dutch mothers and their children the associations of maternal daily total energy intake and intake of macronutrients and micronutrients in the first trimester of pregnancy with blood pressure in children at the age of 6 years. We also assessed whether first-trimester folate, homocysteine and vitamin $\mathrm{B}_{12}$ concentrations in maternal blood were associated with childhood blood pressure. 


\section{Subjects and methods}

\section{Design}

The present study was embedded in the Generation R Study, a population-based prospective cohort study from fetal life onwards in Rotterdam, The Netherlands ${ }^{(21,22)}$. Enrolment in the study was aimed at early pregnancy, but was allowed until the birth of the child. Information about maternal diet and other lifestyle-related variables during pregnancy was collected at enrolment. At the age of 6 years, all participating children and their mothers were invited to a dedicated research centre, to participate in detailed hands-on measurements. The study has been approved by the Medical Ethics Committee of the Erasmus Medical Center, Rotterdam. Written informed consent was obtained from all parents of the participants. The present analysis was limited to Dutch mothers, since the FFQ was validated for the assessment of dietary intake in a Dutch population. We selected mothers who were enrolled in the study before a gestational age of 25 weeks, because we aimed to assess dietary intakes in the first trimester of pregnancy. In total, 4032 Dutch mothers were enrolled before a gestational age of 25 weeks with a median of 13.6 weeks of gestation (90\% range $11.5-20 \cdot 2$ weeks; see Fig. 1). Data on maternal dietary intake or biomarker concentrations were available in 3960 (98\%) of these mothers. We excluded multiple births ( $n$ 104) and stillbirths ( $n$ 29) from the analyses, leaving 3827 Dutch mothers. Of the 3827 singleton live-born children, 2949 (77\%) children attended the follow-up visit at the age of 6 years. Blood pressure was successfully measured in 2863 (97\%) of the children who visited the research centre.

\section{Maternal daily dietary intake}

We assessed maternal dietary intake at enrolment in the study in Dutch mothers using a modified version of the validated semi-quantitative FFQ of Klipstein-Grobusch et al. ${ }^{(23)}$. The FFQ considered food intake over the prior 3 months, thereby covering the dietary intake in the first trimester of pregnancy. The FFQ consisted of 293 items structured according to the meal pattern. Questions included consumption frequency, portion size, preparation method and additions. Portion sizes were estimated using Dutch household measures and photographs of foods showing different portion sizes ${ }^{(24)}$. We used the Dutch food composition table for calculating daily intake of nutritional values ${ }^{(25)}$.

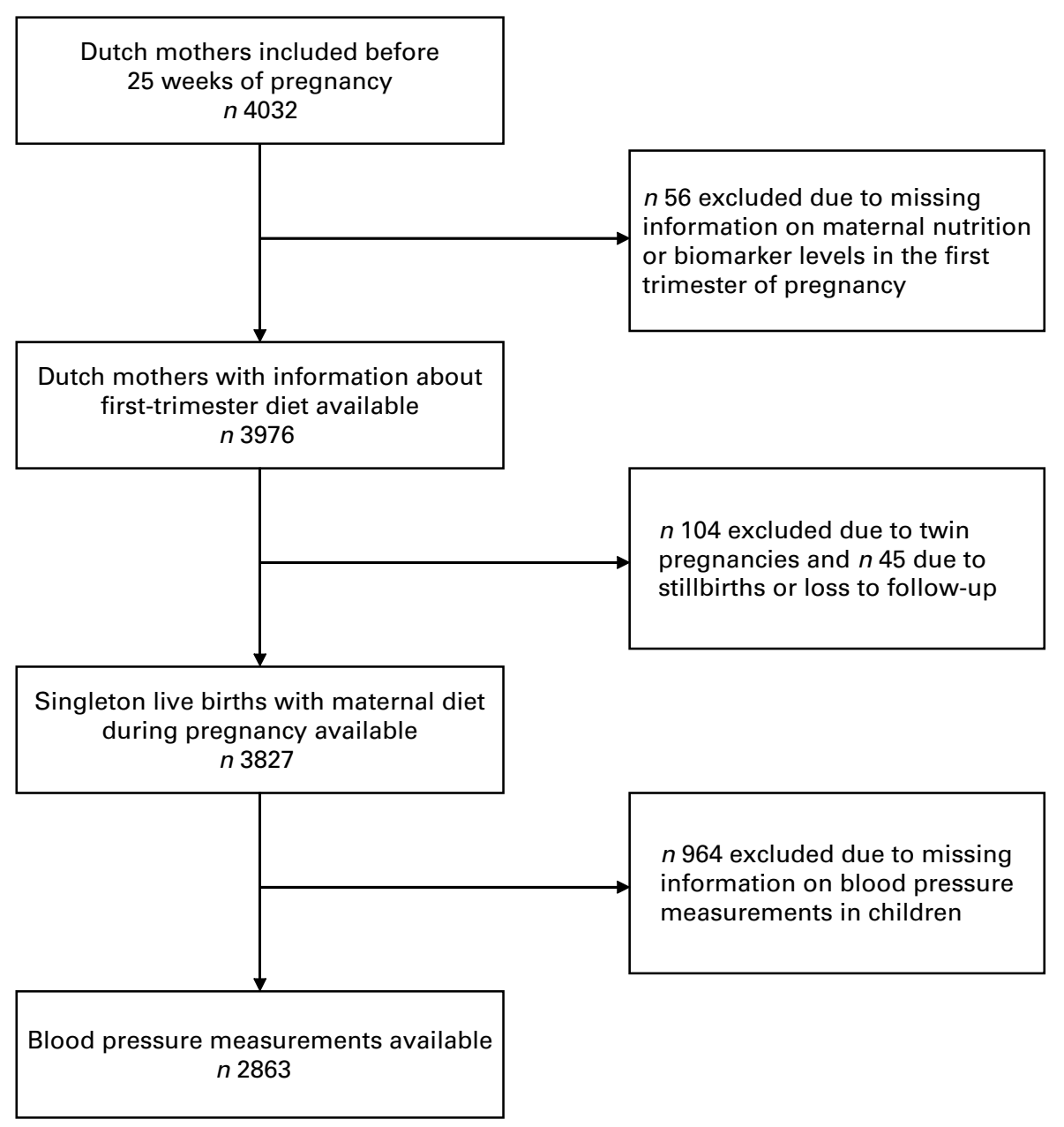

Fig. 1. Flow chart of the participants included for analysis. 


\section{Folic acid supplement intake}

Information on folic acid supplement use $(0.4-0.5 \mathrm{mg})$ and the initiation of supplementation was obtained by questionnaires at the enrolment of the study. We categorised folic acid supplement use into three groups: (1) periconceptional use; (2) start when pregnancy was known; (3) no use during pregnancy. Self-reported folic acid use was validated in a subgroup by serum folate levels in the first trimester, i.e. before 12 weeks of gestation. Within the group of mothers who reported using folic acid supplements ( $n$ 204), the median of serum folate was 23.5 (range $4 \cdot 3-45 \cdot 3$ ) $\mathrm{nmol} / \mathrm{l}$, whereas the median serum folate concentration of mothers who did not report folic acid supplement use ( $n$ 68) was $11 \cdot 1$ (range $4 \cdot 7-29 \cdot 6$ ) $\mathrm{nmol} / \mathrm{l}$. The difference in distribution function (Mann-Whitney test) was statistically significant $(P<0.001)^{(26)}$. Information about folic acid supplement use was available in 2505 subjects (87.5\%).

\section{Folate, homocysteine and vitamin $B_{12}$ concentrations}

In early pregnancy (median 12.9 weeks of gestation, 90\% range 10.6-16.8), venous samples were drawn and stored at room temperature before being transported to the regional laboratory for processing and storage for future studies. Processing was aimed to be completed within a maximum of $3 \mathrm{~h}$ after venous puncture. The samples were centrifuged and thereafter stored at $-80^{\circ} \mathrm{C}^{(21)}$. To analyse folate, homocysteine and vitamin $\mathrm{B}_{12}$ concentrations, EDTA plasma samples (folate and homocysteine) and serum samples (vitamin $\mathrm{B}_{12}$ ) were picked and transported to the Department of Clinical Chemistry at the Erasmus University Medical Center, Rotterdam in 2008. Folate, homocysteine and vitamin $\mathrm{B}_{12}$ concentrations were analysed using an immunoelectrochemoluminence assay on the Architect System (Abbott Diagnostics B.V.). The between-run CV for plasma folate were $8.9 \%$ at $5.6 \mathrm{nmol} / 1,2.5 \%$ at $16.6 \mathrm{nmol} / 1$ and $1.5 \%$ at $33.6 \mathrm{nmol} / 1$, with an analytic range of $1.8-45.3 \mathrm{nmol} / 1$. The same $\mathrm{CV}$ for plasma homocysteine were $3 \cdot 1 \%$ at $7 \cdot 2 \mu \mathrm{mol} / 1,3 \cdot 1 \%$ at $12 \cdot 9 \mu \mathrm{mol} / 1$ and $2 \cdot 1 \%$ at $26 \cdot 1 \mu \mathrm{mol} / 1$, with an anatyc range of $1-50 \mu \mathrm{mol} / 1$. This $\mathrm{CV}$ for serum vitamin $\mathrm{B}_{12}$ was $3.6 \%$ at $142 \mathrm{pmol} / 1,7 \cdot 5 \%$ at $308 \mathrm{pmol} / 1$ and $3 \cdot 1 \%$ at $633 \mathrm{pmol} / 1$, with an analytic range of $44-1476 \mathrm{pmol} / \mathrm{l}$. Plasma concentrations of maternal folate, homocysteine and serum concentrations of vitamin $\mathrm{B}_{12}$ in the first trimester of pregnancy were available in $2305(80.5 \%)$ of the mothers of the children included in the present study. Missing data were mainly due to logistical reasons.

\section{Blood pressure measurements}

Blood pressure measurements in children were conducted around the age of 6 years in a dedicated research centre in the Erasmus Medical Center, Rotterdam, The Netherlands. The child was lying quietly, while systolic blood pressure and diastolic blood pressure were measured at the right brachial artery in a supine position, four times with 1 min intervals. A cuff was selected with a cuff width approximately
$40 \%$ of the arm circumference and long enough to cover $90 \%$ of the arm circumference. We used the validated automatic sphygmomanometer Datascope Accutorr Plus ${ }^{\mathrm{TM}}$ (Mindray DS USA, Inc.) ${ }^{(27)}$. Of all children visiting the research centre, $91.3 \%$ had four successful blood pressure measurements available.

\section{Covariates}

Information on maternal age, pre-pregnancy BMI, parity, alcohol use and smoking habits during pregnancy, and educational level was obtained from questionnaires. Maternal education was defined as highest followed education according to the classification of Statistics Netherlands and categorised into primary, secondary and higher ${ }^{(28)}$. Child sex, gestational age at birth and birth weight were obtained from midwife and hospital registries. Breast-feeding (ever/never) was assessed using questionnaires. Current height and weight were measured without shoes and heavy clothing at the visit at 6 years, and $\mathrm{BMI}\left(\mathrm{kg} / \mathrm{m}^{2}\right)$ was calculated.

\section{Statistical methods}

Differences in child characteristics at the age of 6 years between boys and girls were assessed using the $t$ test and $\chi^{2}$ tests for independent samples. Maternal dietary intake variables were categorised into quintiles. This approach was used for all dietary exposures (total energy, carbohydrate, fat, protein intake and protein:carbohydrate ratio; $\mathrm{Ca}, \mathrm{Fe}$ and $\mathrm{Na}$ intake; folate, homocysteine and vitamin $\mathrm{B}_{12}$ concentrations). We used mixed models to assess the associations between predictors and blood pressure ${ }^{(29)}$. The mixed-model method fits each of the as many as four blood pressure measurements of every child as repeated outcome measures. An advantage of this modelling approach over using the average measure of blood pressure for each child as an outcome is that children with more measurements and less variability in their measurements are assigned more weight than those with fewer measurements, more variability or both ${ }^{(9,30)}$. We used similar mixed models to assess the association of folic acid supplement use with blood pressure at the age of 6 years. All analyses were adjusted for child's sex and age at blood pressure measurement (crude model). Potential covariates were selected based on previous literature ${ }^{(31,32)}$. We assessed crude associations, adjusted for age and sex, of possible covariates with childhood blood pressure. Only the covariates that were significantly associated with systolic or diastolic blood pressure in the present study population were included in our fully adjusted model. The fully adjusted model included maternal age, pre-pregnancy BMI, alcohol use and smoking during pregnancy, educational level, gestational age at birth, birth weight, current BMI and month in which blood pressure measurement was taken. Tests for trends were conducted by using maternal dietary intake variables as the continuous variable in the linear mixed models. We provided the effect per standard deviation increase in the dietary intake variable. In the macronutrient analyses, we used the energy partition method to adjust for energy intake of the other 
macronutrients, since total energy intake and macronutrient intakes were strongly correlated ${ }^{(33)}$. The actual energy derived from the macronutrients was used in the analyses. In the micronutrient analyses, we used the residual nutrient method, and additionally adjusted for total energy intake ${ }^{(33)}$.

Missing values in covariates (ranging from 0 to $15 \%$ ) were multiple-imputed to reduce potential bias associated with missing data ${ }^{(34)}$. We created five imputed datasets and each dataset was analysed separately to obtain the effect sizes and standard errors. The results of all the five imputed analyses were pooled and are presented in the present study. We investigated maternal macronutrient intake, micronutrient intake and maternal biomarker concentrations in pregnancy. Within these exposure groups, variables are correlated (Table S1, available online). To take into account multiple testing, we applied a Bonferroni correction and considered a $P$ value lower than $0 \cdot 017$ (0.05/3 (three exposure groups)) as statistically significant. The mixed models were fitted using the SAS version 9.2 (SAS Institute, Inc.). All other statistical analyses were performed using SPSS version 17.0 for Windows (SPSS, Inc.).

\section{Results}

Table 1 presents the maternal and birth subject characteristics. The mean intake of total energy was $8982 \cdot 8$ (SD $2117 \cdot 3$ ) $\mathrm{kJ} / \mathrm{d}$, Ca 1222 (sD 420) mg/d, Fe 12.1 (sD 3.3) mg/d and $\mathrm{Na} 3314$ (sD 931) $\mathrm{mg} / \mathrm{d}$. The mean birth weight was 3497 (SD 548) g. Child characteristics at the age of 6 years for boys and girls separately are shown in Table 2. Systolic blood pressure and diastolic blood pressure were significantly higher in girls compared with boys $(P<0 \cdot 05)$.

Maternal total daily energy intake and daily intake of carbohydrates, fat and proteins were not associated with childhood systolic and diastolic blood pressure (Table 3). The protein: carbohydrate intake ratio was not associated with childhood

Table 1. Maternal and birth characteristics: the Generation R Study Cohort, Rotterdam, The Netherlands*

(Mean values and standard deviations; medians, $95 \%$ ranges and percentages)

\begin{tabular}{|c|c|c|c|c|c|c|c|c|}
\hline & \multicolumn{4}{|c|}{ Not imputed } & \multicolumn{4}{|c|}{ Imputed } \\
\hline & Mean & SD & Median & $95 \%$ range & Mean & SD & Median & $95 \%$ range \\
\hline \multicolumn{9}{|l|}{ Maternal characteristics } \\
\hline Age (years) & & & $31 \cdot 8$ & $22 \cdot 2-39 \cdot 6$ & & & & \\
\hline Height $(\mathrm{cm})$ & $170 \cdot 8$ & $6 \cdot 4$ & & & & & & \\
\hline Weight (kg) & $68 \cdot 1$ & $12 \cdot 3$ & & & $68 \cdot 1$ & $12 \cdot 2$ & & \\
\hline BMI $\left(\mathrm{kg} / \mathrm{m}^{2}\right)$ & & & $22 \cdot 3$ & $18 \cdot 2-34 \cdot 3$ & & & $22 \cdot 4$ & $18 \cdot 2-34.5$ \\
\hline Parity $\geq 1$ (\%) & & & 38.4 & & & & & \\
\hline \multicolumn{9}{|l|}{ Alcohol use (\%) } \\
\hline No & & & $31 \cdot 8$ & & & & & \\
\hline First trimester only & & & $16 \cdot 7$ & & & & & \\
\hline Continued & & & 51.5 & & & & & \\
\hline \multicolumn{9}{|l|}{ Smoking during pregnancy (\%) } \\
\hline Never & & & $75 \cdot 1$ & & & & & \\
\hline First trimester only & & & $9 \cdot 6$ & & & & & \\
\hline Continued & & & $15 \cdot 3$ & & & & & \\
\hline \multicolumn{9}{|l|}{ Educational level (\%) } \\
\hline Primary & & & $2 \cdot 5$ & & & & & \\
\hline Secondary & & & $36 \cdot 6$ & & & & & \\
\hline Higher & & & $60 \cdot 9$ & & & & & \\
\hline Energy intake $(\mathrm{kJ} / \mathrm{d})$ & $8982 \cdot 8$ & $2117 \cdot 3$ & & & & & & \\
\hline Carbohydrate intake $(\mathrm{g} / \mathrm{d})$ & $262 \cdot 2$ & 74.1 & & & & & & \\
\hline$\%$ of total energy intake & & & $48 \cdot 3$ & $37 \cdot 2-61 \cdot 3$ & & & & \\
\hline Fat intake $(g / d)$ & $86 \cdot 5$ & $24 \cdot 0$ & & & & & & \\
\hline$\%$ of total energy intake & & & $36 \cdot 4$ & $25 \cdot 3-46 \cdot 4$ & & & & \\
\hline Protein intake $(\mathrm{g} / \mathrm{d})$ & $79 \cdot 7$ & 18.9 & & & & & & \\
\hline$\%$ of total energy intake & & & 14.9 & $10 \cdot 7-19.9$ & & & & \\
\hline Ca intake $(\mathrm{mg} / \mathrm{d})$ & $1222 \cdot 3$ & $419 \cdot 9$ & & & & & & \\
\hline Fe intake (mg/d) & $12 \cdot 1$ & 3.3 & & & & & & \\
\hline $\mathrm{Na}$ intake $(\mathrm{mg} / \mathrm{d})$ & $3314 \cdot 3$ & $931 \cdot 3$ & & & & & & \\
\hline \multicolumn{9}{|l|}{ Folic acid use (\%) } \\
\hline No & & & $9 \cdot 6$ & & & & & \\
\hline Started when pregnancy was known & & & 33.7 & & & & & \\
\hline Started periconceptional & & & $56 \cdot 7$ & & & & & \\
\hline Folate levels $(\mathrm{nmol} / \mathrm{l})$ & $20 \cdot 2$ & 8.7 & & & & & & \\
\hline Homocysteine levels $(\mu \mathrm{mol} / \mathrm{l})$ & $7 \cdot 3$ & $2 \cdot 1$ & & & & & & \\
\hline Vitamin $\mathrm{B}_{12}$ levels $(\mathrm{pmol} / \mathrm{l})$ & $193 \cdot 2$ & $87 \cdot 4$ & & & & & & \\
\hline \multicolumn{9}{|l|}{ Birth characteristics } \\
\hline Birth weight (g) & 3497 & 548 & & & & & & \\
\hline Gestational age at birth (weeks) & & & $40 \cdot 3$ & $35 \cdot 9-42 \cdot 3$ & & & & \\
\hline \multicolumn{9}{|l|}{ Sex } \\
\hline Male (\%) & & & $49 \cdot 8$ & & & & & \\
\hline Breast-feeding (never) (\%) & & & $8 \cdot 7$ & & & & $9 \cdot 2$ & \\
\hline
\end{tabular}

* Only covariates with missing data were multiple-imputed. 
Table 2. Child characteristics: the Generation R Study Cohort, Rotterdam, The Netherlands $\dagger$

(Mean values and standard deviations; medians, 95\% ranges and percentages)

\begin{tabular}{|c|c|c|c|c|}
\hline & \multicolumn{2}{|c|}{ Boys ( $n 1427)$} & \multicolumn{2}{|c|}{ Girls (n 1436) } \\
\hline & Mean & SD & Mean & SD \\
\hline \multicolumn{5}{|l|}{ Age (years) } \\
\hline Median & \multirow{2}{*}{\multicolumn{2}{|c|}{$\begin{array}{c}6.0 \\
5.6-7.5\end{array}$}} & \multicolumn{2}{|c|}{$6 \cdot 0$} \\
\hline $95 \%$ range & & & \multicolumn{2}{|c|}{$5 \cdot 6-7 \cdot 1$} \\
\hline Height $(\mathrm{cm})$ & 119.9 & $5 \cdot 7$ & $119 \cdot 1$ & $5 \cdot 6$ \\
\hline Weight (kg) & 23.0 & 3.5 & $22 \cdot 7$ & 3.7 \\
\hline Underweight (\%) & \multicolumn{2}{|c|}{$6 \cdot 4$} & \multicolumn{2}{|c|}{4.0} \\
\hline Normal weight (\%) & \multicolumn{2}{|c|}{$84 \cdot 6$} & \multicolumn{2}{|c|}{$82 \cdot 6$} \\
\hline Overweight (\%) & \multicolumn{2}{|c|}{$9 \cdot 0$} & \multicolumn{2}{|c|}{$13 \cdot 3$} \\
\hline \multicolumn{5}{|l|}{ BMI $\left(\mathrm{kg} / \mathrm{m}^{2}\right)$} \\
\hline Median & \multicolumn{2}{|c|}{$15 \cdot 7$} & \multicolumn{2}{|c|}{$15 \cdot 6$} \\
\hline $95 \%$ range & \multicolumn{2}{|c|}{$13 \cdot 7-18.9$} & \multicolumn{2}{|c|}{$13 \cdot 7-19 \cdot 8$} \\
\hline Systolic blood pressure $(\mathrm{mmHg})$ & $102 \cdot 2$ & $7 \cdot 3$ & $103 \cdot 3^{*}$ & 8.2 \\
\hline Diastolic blood pressure $(\mathrm{mmHg})$ & $60 \cdot 2$ & 6.4 & $61 \cdot 6^{*}$ & 6.5 \\
\hline
\end{tabular}

${ }^{*}$ Mean values were significantly different from those of boys $(P<0.05)$.

†Only covariates with missing data were multiple-imputed.

blood pressure (Table 3). After adjustment for confounders, maternal intake of Fe tended to be inversely associated with childhood systolic blood pressure $(-0.30 \mathrm{mmHg}$ per standard deviation increase in Fe intake (95\% CI - 0.61, 0.01), $P$ for trend 0.06), but not with diastolic blood pressure (Table 4). Maternal intake of $\mathrm{Ca}$ and $\mathrm{Na}$ was not consequently associated with childhood systolic or diastolic blood pressure.

We did not find an association of folic acid supplement use during pregnancy with childhood systolic or diastolic blood pressure (Table 5). The associations of maternal firsttrimester folate, homocysteine and vitamin $\mathrm{B}_{12}$ concentrations with childhood blood pressure are presented in Table 6. We found no consistent associations of maternal first-trimester folate and homocysteine concentrations with childhood systolic blood pressure and diastolic blood pressure in 6-year-old children. Lower maternal first-trimester vitamin $\mathrm{B}_{12}$ concentrations were associated with lower childhood diastolic blood pressure (difference $0.31 \mathrm{mmHg}$ per standard deviation increase in vitamin $\mathrm{B}_{12}$ concentration (95\% CI 0.06 , 0.56), $P$ value for trend 0.02 ), but not with systolic blood pressure. However, the associations between Fe intake and vitamin $\mathrm{B}_{12}$ concentrations with childhood blood pressure did not reach the significance threshold after adjustment for multiple testing.

\section{Discussion}

The results from the present population-based prospective cohort study suggest that maternal daily macronutrient and micronutrient intake in the first trimester of pregnancy is not associated with childhood blood pressure at the age of 6 years. We observed that higher $\mathrm{Fe}$ intake and vitamin $\mathrm{B}_{12}$ concentrations may be associated with a lower childhood systolic and higher diastolic blood pressure, respectively, but we should also consider the effect of multiple testing. After multiple testing correction, none of the results remained significant.

\section{Strengths and limitations}

The main strength of the present study is the prospective design from early life onwards and the large sample size of this population-based cohort. To our knowledge, this is one of the largest prospective studies that examined the associations between the daily maternal intake of micronutrients and macronutrients in the first trimester of pregnancy with childhood blood pressure. We used a FFQ, previously validated in a Dutch population ${ }^{(23)}$, to assess dietary intake of the mothers. Although we have used a validated questionnaire, misclassification of dietary intake can still occur, which might have led to an underestimation of the effect estimates. We measured blood pressure in 6-year-old children using a validated automatic sphygmanometer ${ }^{(27)}$ and acquired multiple blood pressure measurements to minimise measurement error. Furthermore, information about a large number of potential confounders was available. However, some limitations need to be addressed. Of all mothers included before a gestational age of 25 weeks, information on maternal dietary intake was missing for only $1.4 \%$ of all mothers. This nonresponse would lead to biased effect estimates if the associations of maternal dietary intake and childhood blood pressure would be different between mothers included and not included in the analyses. This seems unlikely because biased estimates in large cohort studies mainly arise from loss to follow-up rather than from a non-response at baseline ${ }^{(35)}$. Of all Dutch singleton live-born children with available data on maternal dietary intake during the first trimester of pregnancy, $74.3 \%$ participated in the follow-up measurements at the age of 6 years. Overall, mothers who did not visit the research centre were younger, less well educated, smoked more frequently and used less alcohol during pregnancy. This selective loss to follow-up might have led to biased effect estimates. We also have to acknowledge that the present study population included in the analyses is comprised of relatively healthy women with a higher proportion of folic acid supplement use compared with other populations. This might have resulted in smaller observed differences and might limit generalisability to other populations. Also, maternal dietary intake was only assessed in the first trimester of pregnancy, while dietary intake might change during pregnancy. Although it has been demonstrated that maternal nutritional intake did not change significantly during pregnancy ${ }^{(36)}$, second- or third-trimester maternal diet might be associated with cardiovascular development, and influence childhood blood pressure. Unfortunately, we were not able to assess these associations in the present study. Finally, although we have performed adjustment for various potential confounders, residual confounding might still be an issue due to the observational design of the study.

\section{Maternal macronutrient intake}

Low birth weight is associated with higher blood pressure and CVD in later life ${ }^{(37,38)}$. It has been suggested that these associations might be explained by suboptimal maternal diet ${ }^{(1-3)}$. Historical cohort studies in The Netherlands and China 
Table 3. Associations of maternal macronutrient intake during pregnancy with blood pressure in children at the age of 6 years in a Dutch population $\dagger$ (Regression coefficients and $95 \%$ confidence intervals)

\begin{tabular}{|c|c|c|c|c|c|c|c|c|}
\hline \multirow[b]{3}{*}{ Macronutrients ( $n$ 2554) } & \multicolumn{4}{|c|}{ Systolic blood pressure $(\mathrm{mmHg})$} & \multicolumn{4}{|c|}{ Diastolic blood pressure $(\mathrm{mmHg})$} \\
\hline & \multicolumn{2}{|c|}{ Crude model } & \multicolumn{2}{|c|}{ Adjusted model } & \multicolumn{2}{|c|}{ Crude model } & \multicolumn{2}{|c|}{ Adjusted model } \\
\hline & $\begin{array}{c}\text { Regression } \\
\text { coefficient }\end{array}$ & $95 \% \mathrm{Cl}$ & $\begin{array}{c}\text { Regression } \\
\text { coefficient }\end{array}$ & $95 \% \mathrm{Cl}$ & $\begin{array}{c}\text { Regression } \\
\text { coefficient }\end{array}$ & $95 \% \mathrm{Cl}$ & $\begin{array}{c}\text { Regression } \\
\text { coefficient }\end{array}$ & $95 \% \mathrm{Cl}$ \\
\hline \multicolumn{9}{|l|}{ Total energy intake $(\mathrm{kJ})$} \\
\hline First quintile & Reference & & Reference & & Reference & & Reference & \\
\hline Second quintile & 0.07 & $-0.87,1.01$ & 0.09 & $-0.83,1.00$ & 0.53 & $-0.25,1.31$ & 0.55 & $-0.23,1.32$ \\
\hline Third quintile & -0.15 & $-1.08,0.79$ & 0.04 & $-0.87,0.96$ & 0.11 & $-0.67,0.89$ & 0.19 & $-0.58,0.96$ \\
\hline Fourth quintile & -0.44 & $-1.38,0.50$ & -0.17 & $-1.09,0.75$ & -0.20 & $-0.99,0.58$ & $-0 \cdot 10$ & $-0.88,0.68$ \\
\hline Fifth quintile & -0.14 & $-1.08,0.80$ & -0.03 & $-0.95,0.90$ & 0.30 & $-0.48,1.09$ & 0.33 & $-0.45,1.11$ \\
\hline Trend $\ddagger$ & -0.04 & $-0.34,0.26$ & 0.02 & $-0.27,0.31$ & 0.06 & $-0.19,0.31$ & 0.07 & $-0.17,0.32$ \\
\hline \multicolumn{9}{|l|}{ Carbohydrate intake (kJ) } \\
\hline First quintile & Reference & & Reference & & Reference & & Reference & \\
\hline Second quintile & -0.00 & $-0.94,0.94$ & 0.20 & $-0.75,1.14$ & 0.49 & $-0.29,1.27$ & 0.52 & $-0.28,1.31$ \\
\hline Third quintile & 0.41 & $-0.53,1.35$ & 0.61 & $-0.38,1.60$ & 0.39 & $-0.39,1.17$ & 0.33 & $-0.50,1.16$ \\
\hline Fourth quintile & -0.14 & $-1.08,0.80$ & 0.06 & $-0.99,1.11$ & -0.10 & $-0.88,0.68$ & -0.20 & $-1.09,0.68$ \\
\hline Fifth quintile & $0 \cdot 18$ & $-0.75,1.12$ & 0.37 & $-0.76,1.50$ & 0.65 & $-0.13,1.44$ & 0.47 & $-0.48,1.42$ \\
\hline Trend $\ddagger$ & 0.07 & $-0.23,0.36$ & 0.11 & $-0.26,0.49$ & 0.15 & $-0.10,0.40$ & 0.10 & $-0.21,0.41$ \\
\hline \multicolumn{9}{|l|}{ Fat intake (kJ) } \\
\hline First quintile & Reference & & Reference & & Reference & & Reference & \\
\hline Second quintile & 0.09 & $-0.85,1.02$ & 0.19 & $-0.76,1.14$ & 0.47 & $-0.31,1.25$ & 0.36 & $-0.44,1 \cdot 16$ \\
\hline Third quintile & -0.44 & $-1.38,0.50$ & -0.24 & $-1.27,0.79$ & 0.19 & $-0.59,0.98$ & 0.06 & $-0.81,0.93$ \\
\hline Fourth quintile & -0.55 & $-1.50,0.39$ & -0.27 & $-1.37,0.82$ & -0.44 & $-1.23,0.34$ & -0.68 & $-1.61,0.25$ \\
\hline Fifth quintile & -0.18 & $-1.12,0.75$ & 0.19 & $-1.05,1.43$ & 0.18 & $-0.61,0.96$ & $-0 \cdot 10$ & $-1 \cdot 15,0.94$ \\
\hline Trend $\neq$ & -0.12 & $-0.42,0.17$ & 0.02 & $-0.41,0.44$ & -0.07 & $-0.32,0.18$ & -0.21 & $-0.57,0.14$ \\
\hline \multicolumn{9}{|l|}{ Protein intake (kJ) } \\
\hline First quintile & Reference & & Reference & & Reference & & Reference & \\
\hline Second quintile & -0.75 & $-1.68,0.19$ & -0.62 & $-1.58,0.34$ & -0.19 & $-0.97,0.59$ & -0.04 & $-0.85,0.77$ \\
\hline Third quintile & -0.87 & $-1.81,0.07$ & -0.68 & $-1.71,0.36$ & -0.58 & $-1.36,0.20$ & -0.32 & $-1.19,0.55$ \\
\hline Fourth quintile & -0.60 & $-1.54,0.34$ & -0.34 & $-1.48,0.80$ & -0.30 & $-1.08,0.49$ & 0.06 & $-0.91,1.02$ \\
\hline Fifth quintile & -0.56 & $-1.50,0.38$ & -0.45 & $-1.76,0.84$ & -0.02 & $-0.81,0.76$ & 0.35 & $-0.75,1.44$ \\
\hline Trend & -0.15 & $-0.43,0.17$ & -0.12 & $-0.57,0.33$ & 0.04 & $-0.21,0.28$ & 0.21 & $-0.17,0.59$ \\
\hline \multicolumn{9}{|l|}{ Protein:carbohydrate ratio } \\
\hline First quintile & Reference & & Reference & & Reference & & Reference & \\
\hline Second quintile & $-1 \cdot 11^{*}$ & $-2.05,-0.17$ & -0.90 & $-1.82,0.02$ & -0.63 & $-1.42,0.14$ & -0.38 & $-1 \cdot 16,0.40$ \\
\hline Third quintile & -0.88 & $-1.81,0.05$ & -0.54 & $-1.47,0.39$ & $-0.80^{*}$ & $-1.58,-0.02$ & -0.47 & $-1.25,0.31$ \\
\hline Fourth quintile & -0.87 & $-1.81,0.06$ & -0.50 & $-1.43,0.43$ & -0.64 & $1.42,0.14$ & -0.22 & $-1.01,0.57$ \\
\hline Fifth quintile & $-0.99^{*}$ & $-1.93,-0.06$ & -0.65 & $-1.58,0.29$ & -0.61 & $-1.39,0.17$ & -0.21 & $-1.00,0.58$ \\
\hline Trendł & -0.21 & $-0.51,0.08$ & -0.11 & $-0.41,0.19$ & $-0 \cdot 16$ & $-0.41,0.09$ & -0.05 & $-0.30,0.20$ \\
\hline
\end{tabular}

$* P<0.05$

† Values reflect the difference in blood pressure $(\mathrm{mmHg})$ at the age of 6 years for each quintile of macronutrient intake ( $\mathrm{KJ}$ derived from macronutrients). The crude model is adjusted for child sex and age at blood pressure measurement. The adjusted model is additionally adjusted for maternal age, pre-pregnancy BMI, alcohol use and smoking during pregnancy, educational level, gestational age at birth, birth weight, current BMI and month in which blood pressure measurement was taken and additionally adjusted for energy from the other macronutrients following the energy partition method ${ }^{(1)}$.

$\ddagger$ Tests for trends were conducted using the maternal dietary intake variables as the continuous variable in the linear mixed models. Values reflect the difference in blood pressure (mmHg) per standard deviation increase in macronutrient intake. 
Table 4. Associations of maternal micronutrient intake during pregnancy with blood pressure at the age of 6 years in a Dutch population $\dagger$

(Regression coefficients and $95 \%$ confidence intervals)

\begin{tabular}{|c|c|c|c|c|c|c|c|c|}
\hline \multirow[b]{3}{*}{ Micronutrients ( $n$ 2554) } & \multicolumn{4}{|c|}{ Systolic blood pressure $(\mathrm{mmHg})$} & \multicolumn{4}{|c|}{ Diastolic blood pressure $(\mathrm{mmHg})$} \\
\hline & \multicolumn{2}{|c|}{ Crude model } & \multicolumn{2}{|c|}{ Adjusted model } & \multicolumn{2}{|c|}{ Crude model } & \multicolumn{2}{|c|}{ Adjusted model } \\
\hline & Regression coefficient & $95 \% \mathrm{Cl}$ & Regression coefficient & $95 \% \mathrm{Cl}$ & Regression coefficient & $95 \% \mathrm{Cl}$ & Regression coefficient & $95 \% \mathrm{Cl}$ \\
\hline \multicolumn{9}{|l|}{$\mathrm{Ca}$} \\
\hline First quintile & Reference & & Reference & & Reference & & Reference & \\
\hline Second quintile & 0.44 & $-0.50,1.37$ & 0.47 & $-0.45,1.40$ & $0.80^{\star}$ & $0.02,1.58$ & $0.90^{*}$ & $0.13,1.68$ \\
\hline Third quintile & $0 \cdot 10$ & $-0.83,1.04$ & 0.25 & $-0.68,1 \cdot 18$ & 0.29 & $-0.49,1.07$ & 0.52 & $-0.26,1.30$ \\
\hline Fourth quintile & -0.25 & $-1.18,0.69$ & -0.05 & $-0.98,0.87$ & -0.34 & $-1.12,0.44$ & $-0 \cdot 10$ & $-0.88,0.68$ \\
\hline Fifth quintile & 0.32 & $-0.62,1.26$ & 0.38 & $-0.54,1.31$ & 0.75 & $-0.04,1.53$ & $0.92^{*}$ & $0.14,1.71$ \\
\hline Trend $\ddagger$ & 0.09 & $-0.21,0.38$ & $0 \cdot 10$ & $-0.20,0.39$ & $0 \cdot 15$ & $-0.10,0.40$ & 0.20 & $-0.04,0.45$ \\
\hline \multicolumn{9}{|l|}{$\mathrm{Fe}$} \\
\hline First quintile & Reference & & Reference & & Reference & & Reference & \\
\hline Second quintile & -0.05 & $-0.99,0.88$ & 0.31 & $-0.63,1.25$ & 0.32 & $-0.47,1.10$ & 0.63 & $-0.16,1.43$ \\
\hline Third quintile & -0.57 & $-1.51,0.37$ & -0.06 & $-1.02,0.90$ & $0 \cdot 18$ & $-0.60,0.96$ & 0.70 & $-0.11,1.51$ \\
\hline Fourth quintile & $-0.94^{\star}$ & $-1.87,-0.00$ & -0.34 & $-1.31,0.62$ & -0.22 & $-1.00,0.56$ & 0.32 & $-0.49,1.13$ \\
\hline Fifth quintile & $-1 \cdot 38^{\star \star}$ & $-2.32,-0.44$ & -0.76 & $-1 \cdot 73,0 \cdot 21$ & -0.71 & $-1.50,0.07$ & -0.14 & $-0.96,0.68$ \\
\hline Trend‡ & $-0.48^{\star \star}$ & $-0.78,-0.18$ & -0.30 & $-0.61,0.01$ & -0.23 & $-0.47,0.02$ & -0.06 & $-0.32,0.20$ \\
\hline \multicolumn{9}{|l|}{$\mathrm{Na}$} \\
\hline First quintile & Reference & & Reference & & Reference & & Reference & \\
\hline Second quintile & -0.71 & $-1.65,0.23$ & -0.57 & $-1.50,0.35$ & -0.41 & $-1 \cdot 19,0.38$ & -0.34 & $-1 \cdot 12,0.44$ \\
\hline Third quintile & $-0.98^{\star}$ & $-1.92,-0.04$ & -0.90 & $-1.82,0.02$ & -0.49 & $-1.27,0.30$ & -0.44 & $-1 \cdot 22,0.33$ \\
\hline Fourth quintile & -0.17 & $-1 \cdot 10,0.77$ & -0.24 & $-1 \cdot 16,0.68$ & -0.11 & $-0.89,0.67$ & -0.12 & $-0.89,0.66$ \\
\hline Fifth quintile & -0.08 & $-1.02,0.85$ & -0.08 & $-1.00,0.85$ & -0.30 & $-1.08,0.48$ & -0.27 & $-1.04,0.52$ \\
\hline Trend $\ddagger$ & 0.07 & $-0.22,0.37$ & 0.06 & $-0.24,0.35$ & -0.01 & $-0.25,0.24$ & -0.00 & $-0.25,0.24$ \\
\hline
\end{tabular}


Table 5. Associations of maternal folic acid supplement use during pregnancy with blood pressure at the age of 6 years in a Dutch population* (Regression coefficients and $95 \%$ confidence intervals)

\begin{tabular}{|c|c|c|c|c|c|c|c|c|}
\hline & \multicolumn{4}{|c|}{ Systolic blood pressure $(\mathrm{mmHg})$} & \multicolumn{4}{|c|}{ Diastolic blood pressure $(\mathrm{mmHg})$} \\
\hline & \multicolumn{2}{|c|}{ Crude model } & \multicolumn{2}{|c|}{ Adjusted model } & \multicolumn{2}{|c|}{ Crude model } & \multicolumn{2}{|c|}{ Adjusted model } \\
\hline & $\begin{array}{c}\text { Regression } \\
\text { coefficient }\end{array}$ & $95 \% \mathrm{Cl}$ & $\begin{array}{c}\text { Regression } \\
\text { coefficient }\end{array}$ & $95 \% \mathrm{Cl}$ & $\begin{array}{l}\text { Regression } \\
\text { coefficient }\end{array}$ & $95 \% \mathrm{Cl}$ & $\begin{array}{l}\text { Regression } \\
\text { coefficient }\end{array}$ & $95 \% \mathrm{Cl}$ \\
\hline \multicolumn{9}{|l|}{ Folic acid supplement use ( $n$ 2379) } \\
\hline No $(n 227)$ & 0.64 & $-0.34,1.61$ & 0.09 & $-0.90,1.07$ & 0.46 & $-0.35,1.27$ & -0.03 & $-0.85,0.79$ \\
\hline $\begin{array}{l}\text { Started when pregnancy was } \\
\text { known }(n 797)\end{array}$ & 0.04 & $-0.59,0.66$ & -0.04 & $-0.68,0.60$ & -0.40 & $-0.92,0.12$ & -0.52 & $-1.05,0.04$ \\
\hline Started periconceptional ( $n$ 1355) & Reference & & Reference & & Reference & & Reference & \\
\hline
\end{tabular}

* Values reflect the difference in blood pressure $(\mathrm{mmHg})$ at the age of 6 years for each group of maternal folic acid supplement use. The crude model is adjusted for child sex and age at blood pressure measurement. The adjusted model is additionally adjusted for maternal age, pre-pregnancy BMI, alcohol use and smoking during pregnancy, educational level, gestational age at birth, birth weight, current BMI and month in which blood pressure measurement was taken.

showed that maternal exposure to famine is associated with a higher blood pressure in adult offspring ${ }^{(4,39)}$. The effect of the normal variation in maternal daily energy intake and macronutrient intake on childhood blood pressure has been examined in several studies, but showed inconsistent results ${ }^{(7,8,16)}$. Consistent with previous studies, we did not observe associations of maternal total energy intake during pregnancy and childhood blood pressure ${ }^{(8,40)}$. As suggested by Roseboom et al. ${ }^{(4)}$, it might be that an imbalance of maternal macronutrients, rather than total energy intake, is associated with childhood blood pressure. Using the energy partition method ${ }^{(33)}$, we did not observe associations of maternal daily carbohydrate, fat or protein intake with childhood blood pressure. Previously, two smaller studies from Finland and the Philippines showed conflicting results regarding the associations of maternal fat intake with childhood blood pressure ${ }^{(7,8)}$. The present results suggest that there is no association of maternal fat intake with childhood blood pressure. Also, a previous study showed that a higher maternal protein intake is associated with a lower blood pressure in boys, but these findings were not confirmed in other studies $8,(40,41)$. The inconsistent results might be explained by differences in study populations.

\section{Maternal calcium, iron and sodium intake}

Several studies, including follow-up studies of randomised clinical trials, have shown an association of Ca supplement use during pregnancy with a lower blood pressure in children $^{(11,14)}$. However, maternal $\mathrm{Ca}$ intake from normal dietary intake was not associated with infant and childhood blood pressure $^{(9,14)}$. In line with these studies, we did not find an association between maternal $\mathrm{Ca}$ intake in the first trimester of pregnancy and offspring blood pressure. It should be noted that our population had a high dietary $\mathrm{Ca}$ intake. This could have affected our power to investigate the effects of low $\mathrm{Ca}$ intake on childhood blood pressure. Another explanation might be that mothers who used $\mathrm{Ca}$ supplements also used other micronutrient supplements, and the combined effect of these supplements might lead to a lower blood pressure in the offspring ${ }^{(14)}$.
Animal studies have shown that maternal Fe restriction during pregnancy was associated with a higher blood pressure in the offspring ${ }^{(42,43)}$. In human subjects, Brion et al. ${ }^{(13)}$ observed in a prospective cohort study among 7484 subjects that maternal $\mathrm{Fe}$ supplement use and Fe intake from food sources, assessed in the third trimester of pregnancy, were not associated with offspring blood pressure. Belfort et $a l^{(10)}$ showed in a prospective longitudinal cohort study among 1098 American children an association of maternal Fe supplement use with a higher systolic blood pressure in children. However, maternal Fe dietary intake from food sources, assessed in the first and second trimesters of pregnancy, was not associated with offspring blood pressure at both time points ${ }^{(10)}$. We observed an association of higher maternal Fe intake from food with a lower blood pressure, although the effect size was small and borderline significant. We assessed dietary intake in the first trimester of pregnancy. It might be that part of the differences in results between the present study and other studies can be explained by different timings of the exposure assessment. Animal studies have shown that offspring of Fe-restricted mothers have a higher blood pressure in later life, possibly mediated by cardiovascular adaptations in response to anaemia, which is in line with the present findings ${ }^{(42,44)}$. Previous studies in animals described the associations of maternal $\mathrm{Na}$ intake with childhood blood pressure and suggested that high $\mathrm{Na}$ intake was associated with a higher blood pressure ${ }^{(15,45)}$. In the present study, maternal $\mathrm{Na}$ intake was not associated with childhood blood pressure. However, $\mathrm{Na}$ intake is poorly assessed by the FFQ, which could have led to an underestimation of the effect. Further experimental studies in animals and observational studies in human subjects are needed to assess the associations of maternal micronutrient intake with offspring blood pressure in later life, and to investigate the possible underlying mechanisms.

\section{Maternal folate, homocysteine and vitamin $B_{12}$ concentrations}

Low folate and high homocysteine concentrations during pregnancy have been associated with lower birth weight and pregnancy complications, such as spontaneous abortion 
Table 6. Associations of maternal first-trimester folate, homocysteine and vitamin $B_{12}$ levels with blood pressure at the age of 6 years in a Dutch population $\dagger$ (Regression coefficients and 95\% confidence intervals)

\begin{tabular}{|c|c|c|c|c|c|c|c|c|}
\hline & \multicolumn{4}{|c|}{ Systolic blood pressure $(\mathrm{mmHg})$} & \multicolumn{4}{|c|}{ Diastolic blood pressure $(\mathrm{mmHg})$} \\
\hline & \multicolumn{2}{|c|}{ Crude model } & \multicolumn{2}{|c|}{ Adjusted model } & \multicolumn{2}{|c|}{ Crude model } & \multicolumn{2}{|c|}{ Adjusted model } \\
\hline & Regression coefficient & $95 \% \mathrm{Cl}$ & Regression coefficient & $95 \% \mathrm{Cl}$ & Regression coefficient & $95 \% \mathrm{Cl}$ & Regression coefficient & $95 \% \mathrm{Cl}$ \\
\hline \multicolumn{9}{|c|}{ Maternal folate $(n 2266)$} \\
\hline First quintile & 0.68 & $-0.26,1.63$ & 0.27 & $-0.68,1.23$ & 0.46 & $-0.33,1.25$ & 0.14 & $-0.65,0.94$ \\
\hline Second quintile & 0.50 & $-0.44,1.44$ & 0.41 & $-0.52,1.35$ & 0.46 & $-0.33,1.24$ & 0.41 & $-0.38,1 \cdot 18$ \\
\hline Third quintile & -0.36 & $-1.29,0.57$ & -0.35 & $-1.27,0.58$ & -0.22 & $-1.00,0.56$ & $-0 \cdot 19$ & $-0.96,0.59$ \\
\hline Fourth quintile & 0.46 & $-0.47,1.39$ & 0.36 & $-0.56,1.29$ & 0.60 & $-0.18,1.38$ & 0.56 & $-0.21,1.34$ \\
\hline Fifth quintile & Reference & & Reference & & Reference & & Reference & \\
\hline Trend $\ddagger$ & 0.06 & $-0.24,0.35$ & 0.11 & $-0.18,0.40$ & -0.03 & $-0.28,0.21$ & 0.03 & $-0.21,0.27$ \\
\hline \multicolumn{9}{|c|}{ Maternal homocysteine ( $n$ 2244) } \\
\hline First quintile & Reference & & Reference & & Reference & & Reference & \\
\hline Second quintile & 0.35 & $-0.55,1.26$ & 0.23 & $-0.66,1.12$ & -0.07 & $-0.83,0.68$ & -0.16 & $-0.90,0.59$ \\
\hline Third quintile & 0.42 & $-0.50,1.35$ & 0.22 & $-0.69,1.13$ & -0.21 & $-0.99,0.56$ & -0.33 & $-1.09,0.43$ \\
\hline Fourth quintile & 0.25 & $-0.68,1.19$ & 0.08 & $-0.83,0.99$ & -0.19 & $-0.96,0.58$ & -0.28 & $-1.04,0.48$ \\
\hline Fifth quintile & 0.58 & $-0.35,1.51$ & 0.08 & $-0.84,1.00$ & -0.23 & $-1.01,0.54$ & -0.56 & $-1.33,0.21$ \\
\hline Trendł & -0.00 & $-0.30,0.29$ & -0.00 & $-0.29,0.28$ & -0.19 & $-0.43,0.05$ & -0.18 & $-0.42,0.06$ \\
\hline \multicolumn{9}{|c|}{ Maternal vitamin $\mathrm{B}_{12}(n 2158)$} \\
\hline First quintile & -0.07 & $-1.03,0.88$ & -0.50 & $-1.46,0.45$ & -0.44 & $-1.24,0.35$ & -0.75 & $-1.54,0.05$ \\
\hline Second quintile & -0.75 & $-1.70,0.21$ & $-0.96^{\star}$ & $-1.91,-0.02$ & -0.70 & $-1.50,0.09$ & $-0.88^{*}$ & $-1.66,-0.09$ \\
\hline Third quintile & -0.42 & $-1.37,0.54$ & -0.48 & $-1.42,0.47$ & -0.38 & $-1.18,0.41$ & -0.42 & $-1.21,0.36$ \\
\hline Fourth quintile & -0.11 & $-1.06,0.85$ & -0.24 & $-1.18,0.71$ & -0.15 & $-0.95,0.64$ & -0.24 & $-1.03,0.55$ \\
\hline Fifth quintile & Reference & & Reference & & Reference & & Reference & \\
\hline Trend‡ & 0.06 & $-0.24,0.36$ & 0.18 & $-0.11,0.48$ & 0.22 & $-0.03,0.47$ & $0.31^{*}$ & $0.06,0.56$ \\
\hline
\end{tabular}


and pre-eclampsia ${ }^{(46-49)}$. Low folate and vitamin $\mathrm{B}_{12}$ levels and high homocysteine levels might affect vascular development and subsequently lead to endothelial dysfunction and higher blood pressure ${ }^{(18)}$. A previous study described the associations of supplement intake, including $\mathrm{Fe}$, folic acid and vitamin $\mathrm{B}_{12}$, during pregnancy with a lower systolic blood pressure in children at the age of 2 years ${ }^{(50)}$. However, since the supplement contained a combination of these nutrients, they could not infer which nutrient contributed to the effect.

We did not observe the associations of maternal folate and homocysteine levels during the first trimester of pregnancy with childhood blood pressure in their offspring. Since higher vitamin $\mathrm{B}_{12}$ levels are associated with lower homocysteine levels, and lower homocysteine levels are associated with a lower blood pressure in adults, we expected that higher maternal vitamin $\mathrm{B}_{12}$ concentrations in the blood would be associated with a lower childhood blood pressure. However, the present results show an opposite effect; higher maternal vitamin $B_{12}$ levels were associated with a higher childhood diastolic blood pressure, although the effect size was small and borderline significant. However, after correction for multiple testing, this association was not statistically significant. To the best of our knowledge, this association has not been described before and the underlying mechanisms are not known.

\section{Conclusions}

The present study shows within a population-based cohort that the normal variation in the maternal intake of macronutrients and micronutrients during the first trimester of pregnancy is not associated with childhood blood pressure. We found some indications that high maternal $\mathrm{Fe}$ intake and low maternal vitamin $B_{12}$ levels seemed to be associated with a lower blood pressure in children at the age of 6 years. However, we investigated multiple exposures, the effect sizes are small and the associations were not significant after correction for multiple testing. Further studies are needed to replicate these findings, to elucidate the underlying mechanisms and to assess whether these differences persist in later life.

\section{Supplementary material}

To view supplementary material for this article, please visit http://dx.doi.org/10.1017/S0007114513000676

\section{Acknowledgements}

The Generation $\mathrm{R}$ study was conducted by the Erasmus Medical Center in close collaboration with the School of Law and Faculty of Social Sciences of Erasmus University Rotterdam, the Municipal Health Service Rotterdam area, Rotterdam, the Rotterdam Homecare Foundation, Rotterdam and the Stichting Trombosedienst \& Artsenlaboratorium Rijnmond, Rotterdam. We gratefully acknowledge the contributions of general practitioners, hospital, midwives and pharmacies in Rotterdam. The first phase of the Generation $\mathrm{R}$
Study is made possible by financial support from the Erasmus Medical Center, Rotterdam, Erasmus University Rotterdam and The Netherlands Organization for Health Research and Development (ZonMw). Additional support was provided by a grant from the Dutch Kidney Foundation (C08.2251) and a grant from the Dutch Heart Foundation (no. 2008B114). V. W. V. J. received an additional grant from The Netherlands Organization for Health Research and Development (ZonMw 90700303, 916.10159). L. C. L. v. d. H. and H. R. T. were responsible for the statistical analyses, the interpretation of the data, and the revisions of the manuscript. L. C. L. v. d. H. and H. R. T. also wrote the first draft of the manuscript. V. W. V. J. supervised L. C. L. v. d. H. with data-analysis, interpretation of the data, and writing of the manuscript. L. L. d. J., D. H. M. H., E. A. P. S. and A. J. v. d. H. contributed to the interpretation of the data, and critically revised the manuscript. A. H. and V. W. V. J. initiated and designed the study, were responsible for the infrastructure in which the study was conducted, contributed to the original data collection, and critically revised the manuscript for important intellectual content. All authors read and approved of the final version of the manuscript. All the authors declare that there are no competing interests.

\section{References}

1. Barker DJ (1995) Fetal origins of coronary heart disease. BMJ 311, 171-174

2. Gluckman PD, Hanson MA, Cooper C, et al. (2008) Effect of in utero and early-life conditions on adult health and disease. $N$ Engl J Med 359, 61-73.

3. Jaddoe VW (2008) Fetal nutritional origins of adult diseases: challenges for epidemiological research. Eur J Epidemiol 23, $767-771$.

4. Roseboom TJ, van der Meulen JH, Ravelli AC, et al. (2001) Effects of prenatal exposure to the Dutch famine on adult disease in later life: an overview. Mol Cell Endocrinol 185, 93-98.

5. Brawley L, Itoh S, Torrens C, et al. (2003) Dietary protein restriction in pregnancy induces hypertension and vascular defects in rat male offspring. Pediatr Res 54, 83-90.

6. Ozaki T, Nishina H, Hanson MA, et al. (2001) Dietary restriction in pregnant rats causes gender-related hypertension and vascular dysfunction in offspring. J Physiol 530, 141-152.

7. Aaltonen J, Ojala T, Laitinen K, et al. (2008) Evidence of infant blood pressure programming by maternal nutrition during pregnancy: a prospective randomized controlled intervention study. J Pediatr 152, 79-84, 84 e71-72.

8. Adair LS, Kuzawa CW \& Borja J (2001) Maternal energy stores and diet composition during pregnancy program adolescent blood pressure. Circulation 104, 1034-1039.

9. Bakker R, Rifas-Shiman SL, Kleinman KP, et al. (2008) Maternal calcium intake during pregnancy and blood pressure in the offspring at age 3 years: a follow-up analysis of the Project Viva cohort. Am J Epidemiol 168, 1374-1380.

10. Belfort MB, Rifas-Shiman SL, Rich-Edwards JW, et al. (2008) Maternal iron intake and iron status during pregnancy and child blood pressure at age 3 years. Int J Epidemiol 37, 301-308.

11. Belizan JM, Villar J, Bergel E, et al. (1997) Long-term effect of calcium supplementation during pregnancy on the blood pressure of offspring: follow up of a randomised controlled trial. BMJ 315, 281-285. 
12. Bergel E \& Barros AJ (2007) Effect of maternal calcium intake during pregnancy on children's blood pressure: a systematic review of the literature. BMC Pediatr 7, 15.

13. Brion MJ, Leary SD, Smith GD, et al. (2008) Maternal anemia, iron intake in pregnancy, and offspring blood pressure in the Avon Longitudinal Study of Parents and Children. Am J Clin Nutr 88, 1126-1133.

14. Gillman MW, Rifas-Shiman SL, Kleinman KP, et al. (2004) Maternal calcium intake and offspring blood pressure. Circulation 110, 1990-1995.

15. Koleganova N, Piecha G, Ritz E, et al. (2011) Both high and low maternal salt intake in pregnancy alter kidney development in the offspring. Am J Physiol Renal Physiol 301, F344-F354.

16. Leary SD, Ness AR, Emmett PM, et al. (2005) Maternal diet in pregnancy and offspring blood pressure. Arch Dis Child 90, 492-493.

17. McGarvey ST, Zinner SH, Willett WC, et al. (1991) Maternal prenatal dietary potassium, calcium, magnesium, and infant blood pressure. Hypertension 17, 218-224.

18. Oosterbaan AM, Steegers EA \& Ursem NT (2012) The effects of homocysteine and folic acid on angiogenesis and VEGF expression during chicken vascular development. Microvasc Res 83, 98-104.

19. Martin H, Lindblad B \& Norman M (2007) Endothelial function in newborn infants is related to folate levels and birth weight. Pediatrics 119, 1152-1158.

20. Genser D, Prachar H, Hauer R, et al. (2006) Homocysteine, folate and vitamin $\mathrm{B}_{12}$ in patients with coronary heart disease. Ann Nutr Metab 50, 413-419.

21. Jaddoe VW, Bakker R, van Duijn CM, et al. (2007) The Generation R Study Biobank: a resource for epidemiological studies in children and their parents. Eur J Epidemiol 22, 917-923.

22. Jaddoe VW, van Duijn CM, van der Heijden AJ, et al. (2010) The Generation R Study: design and cohort update 2010. Eur J Epidemiol 25, 823-841.

23. Klipstein-Grobusch $\mathrm{K}$, den Breeijen JH, Goldbohm RA, et al. (1998) Dietary assessment in the elderly: validation of a semiquantitative food frequency questionnaire. Eur J Clin Nutr 52, 588-596.

24. Donders-Engelen M, van der Heijden L \& Hulshof KFAM (2003) Tabel Maten en gewichten (Tables of Measures and Weights), 2nd ed. Zeist: University of Wageningen.

25. Netherlands-Nutrition-Centre (2006) Nevo: Dutch Food Composition Database 2006. The Hague: Netherlands-NutritionCentre.

26. Timmermans S, Jaddoe VW, Hofman A, et al. (2009) Periconception folic acid supplementation, fetal growth and the risks of low birth weight and preterm birth: the Generation R Study. Br J Nutr 102, 777-785.

27. Wong SN, Tz Sung RY \& Leung LC (2006) Validation of three oscillometric blood pressure devices against auscultatory mercury sphygmomanometer in children. Blood Press Monit 11, 281-291.

28. Statistics Netherlands (2004) Standaard onderwijsindeling 2003 (Standardised Classification of Educational Level). Voorburg/Heerlen: Statistics Netherlands.

29. Laird NM \& Ware JH (1982) Random-effects models for longitudinal data. Biometrics 38, 963-974.

30. Gillman MW \& Cook NR (1995) Blood pressure measurement in childhood epidemiological studies. Circulation $\mathbf{9 2}$, 1049-1057.

31. Lawlor DA, Najman JM, Sterne J, et al. (2004) Associations of parental, birth, and early life characteristics with systolic blood pressure at 5 years of age: findings from the
Mater-University study of pregnancy and its outcomes. Circulation 110, 2417-2423.

32. Lawlor DA \& Smith GD (2005) Early life determinants of adult blood pressure. Curr Opin Nephrol Hypertens 14, 259-264.

33. Willett WC, Howe GR, Kushi LH (1997) Adjustment for total energy intake in epidemiologic studies. Am J Clin Nutr 65 , 1220S-1228S (discussion 1229S-1231S).

34. Sterne JA, White IR, Carlin JB, et al. (2009) Multiple imputation for missing data in epidemiological and clinical research: potential and pitfalls. BMJ 338, b2393.

35. Nohr EA, Frydenberg M, Henriksen TB, et al. (2006) Does low participation in cohort studies induce bias? Epidemiology 17, 413-418.

36. Cuco G, Fernandez-Ballart J, Sala J, et al. (2006) Dietary patterns and associated lifestyles in preconception, pregnancy and postpartum. Eur J Clin Nutr 60, 364-371.

37. Huxley RR, Shiell AW \& Law CM (2000) The role of size at birth and postnatal catch-up growth in determining systolic blood pressure: a systematic review of the literature. J Hypertens $\mathbf{1 8}, 815-831$.

38. Eriksson JG, Forsen T, Tuomilehto J, et al. (2001) Early growth and coronary heart disease in later life: longitudinal study. BMJ 322, 949-953.

39. Li Y, Jaddoe VW, Qi L, et al. (2011) Exposure to the Chinese famine in early life and the risk of hypertension in adulthood. J Hypertens 29, 1085-1092.

40. Roseboom TJ, van der Meulen JH, van Montfrans GA, et al. (2001) Maternal nutrition during gestation and blood pressure in later life. J Hypertens 19, 29-34.

41. Webb AL, Conlisk AJ, Barnhart HX, et al. (2005) Maternal and childhood nutrition and later blood pressure levels in young Guatemalan adults. Int J Epidemiol 34, 898-904.

42. Lewis RM, Petry CJ, Ozanne SE, et al. (2001) Effects of maternal iron restriction in the rat on blood pressure, glucose tolerance, and serum lipids in the 3-month-old offspring. Metabolism 50, 562-567.

43. Gambling L, Dunford S, Wallace DI, et al. (2003) Iron deficiency during pregnancy affects postnatal blood pressure in the rat. J Physiol 552, 603-610.

44. Crowe C, Dandekar P, Fox M, et al. (1995) The effects of anaemia on heart, placenta and body weight, and blood pressure in fetal and neonatal rats. J Physiol 488, 515-519.

45. Porter JP, King SH \& Honeycutt AD (2007) Prenatal high-salt diet in the Sprague-Dawley rat programs blood pressure and heart rate hyperresponsiveness to stress in adult female offspring. Am J Physiol Regul Integr Comp Physiol 293, R334-R342.

46. George L, Mills JL, Johansson AL, et al. (2002) Plasma folate levels and risk of spontaneous abortion. JAMA $\mathbf{2 8 8}$, $1867-1873$.

47. Hogeveen M, Blom HJ \& den Heijer M (2012) Maternal homocysteine and small-for-gestational-age offspring: systematic review and meta-analysis. Am J Clin Nutr 95, 130-136.

48. Parazzini F, Chiaffarino F, Ricci E, et al. (2011) Homocysteine, red cell, and plasma folate concentrations and birth weight in Italian women: results from a prospective study. J Matern Fetal Neonatal Med 24, 427-431.

49. Ray JG \& Laskin CA (1999) Folic acid and homocyst(e)ine metabolic defects and the risk of placental abruption, preeclampsia and spontaneous pregnancy loss: a systematic review. Placenta 20, 519-529.

50. Vaidya A, Saville N, Shrestha BP, et al. (2008) Effects of antenatal multiple micronutrient supplementation on children's weight and size at 2 years of age in Nepal: follow-up of a double-blind randomised controlled trial. Lancet 371, 492-499. 